\title{
Seroepidemiology of leptospirosis and molecular characterization of the first Leptospira strain isolated from Fernando de Noronha archipelago, Brazil
}

\author{
Jean Carlos Silva ${ }^{1}$, Maria Marvulo ${ }^{2}$, Fernando Ferreira ${ }^{3}$, Ricardo Augusto Dias ${ }^{3}$, José \\ Ferreira Neto ${ }^{3}$, Marcos Heinemann ${ }^{3}$, Geraldo Andrade Filho ${ }^{1}$, Gisele Souza ${ }^{3}$, Carlos Lima \\ Filho $^{4}$, Fernando Jorge Magalhães ${ }^{4}$, Walter Lilenbaum ${ }^{5}$, Odir Dellagostin ${ }^{6}$, Natasha de \\ Oliveira $^{6}$, Sérgio Jorge ${ }^{6}$, Frederico Kremer ${ }^{6}$, Cassia Santos ${ }^{7}$, Stephanie Esteves ${ }^{7}$, and Bruno \\ Miotto $^{7}$ \\ ${ }^{1}$ Universidade Federal Rural de Pernambuco \\ ${ }^{2}$ Faculdade Max Plank \\ ${ }^{3}$ Universidade de São Paulo \\ ${ }^{4}$ Unidade de Vigilância em Saúde \\ ${ }^{5}$ Universidade Federal Fluminense \\ ${ }^{6}$ Universidade Federal de Pelotas \\ ${ }^{7}$ Universidade de Santo Amaro
}

July 20, 2020

\begin{abstract}
Leptospirosis has been widely reported in insular environments worldwide, characterizing a major public health threat. Although low genetic biodiversity is expected in these regions, the introduction of domestic and synanthropic mammals may contribute to the wider diversity leptospiral strains in insular settings. This study proposes a large-scale investigation of Leptospira infection in animals from Fernando de Noronha archipelago, Brazil. A total of 1,265 blood samples from domestic ( $\mathrm{n}=682$ ), synanthropic $(\mathrm{n}=133)$ and wild $(\mathrm{n}=450)$ animals were collected between 2007 and 2014, totaling 12 species. The presence of anti-Leptospira spp. antibodies was investigated by the Microscopic Agglutination Test (MAT) and kidney samples from synanthropic rodents were collected for the isolation of Leptospira spp. The leptospires recovered were further characterized by MAT with polyclonal antibodies, whole genome sequencing and Multilocus Sequence Typing (MLST). The MAT results revealed the presence of agglutinins in 90 samples $(7.1 \%)$, and the most frequently found serogroup was Icterohaemorrhagiae (n=57) in practically all species included. Viable leptospires were recovered from one brown rat, and characterization revealed that the isolate belongs to L. interrogans serogroup Pyrogenes. This study stands as the most comprehensive investigation of Leptospira spp. infection in Fernando de Noronha archipelago, also providing the characterization of the first leptospiral strain ever isolated from an insular setting in Brazil. The results suggest that synanthropic rodents play a major role in the transmission of leptospirosis among wildlife and domestic species in the archipelago.
\end{abstract}

\section{Introduction}

Leptospirosis is a zoonotic disease of widespread distribution and increasingly global importance caused by pathogenic bacteria of the genus Leptospira (Cerqueira and Picardeau, 2009). It can affect virtually any mammalian species, which may harbor the pathogen in their renal tubules and shed the bacteria via urine, contributing greatly to the spread of leptospires into the environment (Faine et al., 1999). 
Humans living in urban communities with poor sanitation are highly susceptible to infection, and although rodents are considered the main source of infection in such conditions (Felzemburgh et al., 2014), wildlife and domestic animals have been increasingly attributed to human cases of leptospirosis, particularly in rural areas and underdeveloped tropical regions (Barragan et al., 2016; Biscornet et al., 2017; Zarantonelli et al., 2018). The annual global incidence of the disease in humans is estimated at 1.03 million, leading to nearly 60,000 deaths every year (Costa et al., 2015). Still, leptospirosis is typically difficult to distinguish from other acute febrile illnesses, and the real global incidence tends to be much higher.

Leptospirosis has been extensively reported in insular environments across the world (Victoriano et al., 2009; Petrakovsky et al., 2014; Dietrich et al., 2018; Guernier et al., 2018; Pratt and Rajeev, 2018). Small tropical islands generally have the highest morbidity and mortality, thus characterizing the disease as a major health issue in these locations (Costa et al., 2015). For example, in the Seychelles, leptospirosis was identified as the major health threat for human populations (Biscornet et al., 2017). Similarly, other locations such as Mayotte island (Desvars et al., 2013), Sri Lanka (Warnasekara et al., 2019) and French West Indies (Cassadou et al., 2016) have also reported numerous cases of human leptospirosis. In addition, travel-related leptospirosis is highly associated with tourist activities in tropical regions, and the majority of tourists with confirmed leptospirosis have been originally infected in tropical islands (Bandara et al., 2014; De Vries et al., 2018).

Despite low genetic biodiversity is usually expected in restricted territories, leptospiral diversity in islands can be largely influenced by environmental factors such as geography, soil, climate, biotic interactions and anthropogenic activities (Desvars et al., 2013). Indeed, a surprisingly high diversity of leptospiral strains and different animal reservoirs have been described in the Caribbean islands (Valverde et al., 2013), South West Indian Ocean islands (Guernier et al., 2016; Dietrich et al., 2018), and Pacific islands (Guernier et al., 2018), thus indicating complex interactions between invasive species, native fauna and highly diversified environmental conditions. The evolutionary drivers of such diversity are poorly understood, however it is assumed that different leptospires can be introduced onto insular environments along with domestic and synanthropic species, such as rodents, cattle, goats, sheep, pigs, poultry, domestic dogs and cats (Russell et al., 2018). Such range of invasive mammals may boost the introduction of a highly variable number of leptospiral strains, which may adapt rapidly to new environments and available wildlife hosts (Desvars et al., 2013).

Brazil currently stands as the country with most reported cases of human leptospirosis in Latin America (Schneider et al., 2017), with an average of 3,890 cases annually. Despite the major burden of the disease, the disease in Brazilian islands has been overlooked and leptospiral biodiversity circulating among insular fauna is unknown.

Fernando de Noronha is an inhabited oceanic archipelago composed of 21 islands and islets located approximately $354 \mathrm{~km}$ offshore from the Brazilian Northeast coast. The main island has nearly 3,000 habitants and a total area of $18.6 \mathrm{~km}^{2}$. The island is regarded as a World Natural Heritage site by UNESCO, and the concurrent tourist population is roughly twice the resident population, making Fernando de Noronha one of the most sought-after destinations in Brazil. Invasive livestock has been introduced in the island since 1731 including goats, poultry, cattle, and horses, which are currently bred in backyard conditions by local farmers (Russell et al., 2018). Dogs and cats were also introduced, and predatory behavior of feral cats currently poses as a major threat for the local fauna (Dias et al., 2017). Synanthropic rodents (Rattus rattus, Rattus norvegicus, and Mus musculus ) were first introduced by Portuguese and French colonizers, and the density of black rats is now estimated at 3,700 individuals $/ \mathrm{km}^{2}$ in the main island (Russell et al., 2018).

Although previous cases of human leptospirosis have been reported in Fernando de Noronha by the local authorities, only one study have accessed leptospiral infection in the island (De Morais et al., 2018). Leptospirosis in Fernando de Noronha may result from an intense interaction with animal reservoirs and defining their role on the transmission dynamics is pivotal to prevent infection of local habitants and tourists. This study proposes the first large-scale investigation of Leptospira infection in synanthropic, domestic and wild animals from Fernando de Noronha, Brazil, and describes the molecular and serological characterization of 
the first leptospiral strain isolated on the island.

\section{Material and Methods}

\section{Study Area}

Fernando de Noronha is a small archipelago located in the tropical Atlantic Ocean $\left(3^{\circ} 51^{\prime} \mathrm{S} / 32^{\circ} 25^{\prime} \mathrm{W}\right)$, with a territorial area of $18.6 \mathrm{~km}^{2}$ (IBGE, 2019). It has a tropical climate with mean temperatures around $24^{\circ} \mathrm{C}$ (R. Dias et al., 2011). The island was discovered in 1503, but colonization started only in 1630 by the Dutch and in 1736 by the French. Portuguese colonization followed almost instantly, intensifying the militarization process of the archipelago, also bringing the first livestock animals (Grossman et al., 2010). Currently Fernando de Noronha is part of the Pernambuco State, and it is composed by two federal protected areas: (a) a marine national park (PARNAMAR), currently labeled as Category II of the International Union for Conservation of Nature (IUCN), and which covers $53 \%$ of the terrestrial area of the main island and all the secondary islands; and (b) an environmental protection area (APA), located around the inhabited area of the main island and labeled as Category VI of the IUCN. The population was estimated at 3,061 in 2019 (IBGE, 2019), and the concurrent tourist population is roughly twice the resident population.

The local fauna is relatively diversified; the Noronha skink (Trachylepis atlantica ) (Gasparini et al., 2007), the Noronha worm lizard (Amphisbaena ridleyi) and three land birds (Elaenia ridleyana, Vireo gracilirostris and Zenaida auriculata noronha) are endemic species from the archipelago. House geckos (Hemidactylus mabouia), rococo toads (Rhinella jimi), chickens, cats, dogs, horses, goats, sheep, cattle and tree frogs (Scinax sp.) are invasive species also found in the archipelago, as well as rocky cavies (Kerodon rupestris ) and tegu lizards (Salvator merianae ) (Dias et al., 2017). Three introduced rodent species coexist in the archipelago: Rattus rattus, Rattus norvegicus, and Mus musculus .

\section{Samples and study design}

A total of 1.265 serum samples from domestic $(n=682)$, synanthropic $(n=133)$, and wild animals $(n=450)$ were taken from different animal species to investigate the presence of anti-Leptospira spp. agglutinins. Twelve animal species were sampled, including 100 chickens, 220 cats, 146 dogs, 105 cattle, 83 sheep, 12 goats, 16 horses, 108 black rats (Rattus rattus ), 25 Norway rats (Rattus norvegicus ), 435 cattle egrets (Bubulcus ibis ), 13 tegu lizards (Salvator merianae), and two rock cavies (Kerodon rupestris ).

Since no reliable estimates for the wild and domestic animal populations were available prior the study period, a convenience sampling was performed. The samples were obtained between 2007 and 2014. All samples were obtained exclusively in the main island of Fernando de Noronha, although the cattle egrets only used the main island during the day for foraging, while nesting in multiple islets of the archipelago. A total of 12 sampling sites were systematically used in the main island, all located at the APA territory.

Rodents and rock cavies were captured using Tomahawk live-traps daily baited with pineapple slices at five $\mathrm{pm}$ and checked in the next morning. Cattle egrets were captured at the waste treatment station unit and were physically restrained by using nets and gloves. Tegu lizards were captured using tunnel traps made with a 1-meter segment of plastic pipe with one end closed and the funnel traps were installed in shaded places with an inclination of $20^{\circ}$, preventing that the captured lizard could escape. Additionally, tomahawk live-traps daily baited with one piece of raw chicken or fish early in the morning were used. The domestic animals were contained with the help of their owners.

Blood samples from all domestic species were collected from the jugular, cephalic or saphenous vein, and drawn into BD Vacutainer tubes (BD Diagnostics, New Jersey, USA) to obtain serum samples. Rodents were anaesthetized using ketamine hydrochloride $(40-90 \mathrm{mg} / \mathrm{kg})$ and xylazine hydrochloride $(2-5 \mathrm{mg} / \mathrm{kg})$ and blood samples $(3 \mathrm{~mL})$ were collected by cardiac puncture. Additionally, 12 brown rats and eight black rats were euthanized in a hermetically sealed box containing a cotton wool soaked with isoflurane. Rock cavies were anaesthetized using ketamine hydrochloride $(10 \mathrm{mg} / \mathrm{Kg})$ and xylazine hydrochloride $(2 \mathrm{mg} / \mathrm{kg})$, and blood samples $(0.5 \mathrm{~mL})$ were collected from the saphenous vein. Cattle-egrets were anaesthetized using ketamine hydrochloride $(20-30 \mathrm{mg} / \mathrm{kg}$ ) and xylazine hydrochloride $(2-4 \mathrm{mg} / \mathrm{kg})$, and blood samples were collected from 
the jugular vein or by cardiac puncture. Tegus were physically contained and blood samples were collected by caudal vein puncture.

\section{Leptospira spp. serological testing}

The presence of serum anti-Leptospira spp. agglutinins was determined by the Microscopic Agglutination Test (MAT). A panel of 24 strains of live Leptospira including the serovars Andamana, Australis, Autumnalis, Bataviae, Bratislava, Butembo, Canicola, Castellonis, Copenhageni, Cynopteri, Grippotyphosa, Hardjo (strain hardjoprajtino), Hebdomadis, Icterohaemorrhagiae, Javanica, Panama, Pomona, Pyrogenes, Sentot, Shermani, Tarassovi, Whitcombi, and Wolffi was used, and a saprophytic serovar Patoc of L. biflexa was used as an internal control. Endpoint titers were determined using two-fold dilutions until the last well showing $50 \%$ agglutination was recorded. The final titer was determined by the reciprocal of the positive highest dilution. The cutoff for a positive agglutination reaction was defined as a titer [?]100. For each positive sample, the most probable infecting serogroup was the one presenting the highest titers.

\section{Leptospira spp. culturing}

Kidney samples from 20 euthanized brown rats were collected aseptically for Leptospira culturing. Isolation of leptospires was performed as previously described (Faine et al., 1999). Briefly, samples were macerated and diluted 1:10 in phosphate-buffered saline (PBS, pH 7.4; $\mathrm{NaCl} 0.137 \mathrm{M}$; KCl 0.0027 M; Na2HPO4 0.01 M; KH2PO4 $0.0018 \mathrm{M} / \mathrm{L}$ ), then $1 \mathrm{~mL}$ of the diluted samples was seeded into $9 \mathrm{~mL}$ of liquid EMJH medium enriched with a selective supplement (Nalidixic acid, $50 \mathrm{mg} / \mathrm{L}$; Cycloheximide, $100 \mathrm{mg} / \mathrm{L}$; Chloramphenicol, $5 \mathrm{mg} / \mathrm{L}$ and Neomycin, $5 \mathrm{mg} / \mathrm{L}$ ). Cultures were incubated at $30 \mathrm{oC}$ in for a period of 12 to $24 \mathrm{~h}$ and then seeded in the semi-solid EMJH medium without the selective supplement. The tubes were incubated at 28 $\operatorname{deg} \mathrm{C}$ for 12 weeks and examined weekly by dark-field microscopy to evaluate the presence of spirochetes.

\section{Characterization of the isolate}

The isolate was serologically characterized using polyclonal antibodies according to previous recommendation (Dikken and Kmety, 1978). A panel of 34 specific antisera representing 28 serogroups was used (Andamana, Australis, Autumnalis, Ballum, Bataviae, Canicola, Celledoni, Codice, Cynopteri, Djasiman, Grippotyphosa, Hebdomadis, Holland, Icterohaemorrhagiae, Javanica, Louisiana, Lyme, Manhao, Mini, Panama, Pomona, Pyrogenes, Ranarum, Sarmin, Sejroe, Semaranga, Shermani and Tarassovi), and serogroup identification was confirmed by the identification of the highest titration against specific representative serovars included in the panel.

For molecular characterization, DNA from the isolated strain was extracted using Illustra Bacterium Genomic Prep Mini Spin kit following the manufacturer's instructions (GE Healthcare, Sao Paulo, SP, Brazil). The complete genome was sequenced through an Ion Torrent Personal Genome Machine (PGM) (Life Technologies, Saint Aubin, France) sequencing platform, using a 316 chip (Life Technologies) and single-end libraries to generate readings of 400 bpon the BAM format, which were then converted to the FASTQ format with the bamTofastq tool from the BEDTools toolset. For the identification of Leptospira species, the generated contigs were aligned using BLAST against the Multilocus Sequence Typing (MLST) sequence sets proposed elsewhere (Boonsilp et al., 2013). The allelic profile and sequence type obtained (ST) was compared to other publicly available sequences from the PubMLST (http://pubmlst.org/leptospira).

\section{Ethical Considerations}

The procedures described with animals have been approved by the Ethical Committee of the University of Sao Paulo (protocol CEUA no 1921061113) and all efforts were made to minimize animal suffering. The euthanasia procedures conducted were in strict accordance with the CONCEA recommendations (National Council for Control of Animal Experimentation) of Brazil. All captures of wild animals were approved by the Brazilian Ministry of Environment (Sisbio no 16484-1).

\section{Results}


Out of the 1.265 animals sampled, 90 (7.1\%) tested positive by MAT. Seropositivity for Leptospira was heterogeneous among species, and anti-Leptospira agglutinins were found in $14.3 \%$ of the synanthropic rodents (19/133), 9.4\% of the domestic animals (64/682), and $1.6 \%$ of the wild animals included $(7 / 450)$. Equines and tegu lizards were the most seroreactive species, with seroreactivity of $62.5 \%$ and $30.8 \%$, respectively. Conversely, none of the rock cavies had anti-Leptospira agglutinins, and only three out of the 435 cattle egrets tested positive $(0.7 \%)$. Regarding the other species sampled, $4 \%$ of chickens tested positive (4/100), while $5 \%$ of cats $(11 / 220), 6 \%$ of sheep (5/83), $9.6 \%$ of dogs (14/146), $16,7 \%$ of goats $(2 / 12)$, and $17.1 \%$ of cattle (18/105) presented detectable agglutinins by MAT. Seroreactivity rates of Norway rats and brown rats were $12 \%(3 / 25)$ and $14.8 \%(16 / 108)$, respectively. Table 1 shows the seropositivity according to the species studied and most likely infecting serogroups found among the seroreactive animals.

Table 1: Number and percentage of animals presenting anti-Leptospira spp. agglutinins according to the reacting serogroups and the highest titration found for each animal species, July 2007 to April 2014, Fernando de Noronha, Brazil.

\section{TABLE 1}

High titers ([?]800) were found in 10 animals, of which nine presented the highest titration against serogroup Icterohaemorrhagiae (sorovar Copenhageni). However, the highest titer (6,400 against Australis serogroup) was found in a dog sample. Figure 1 shows the distribution of the most likely infecting serogroups found according to the species sampled.

\section{FIGURE 1}

Figure 1: Distribution of the most likely infecting serogroups according to the species sampled.

Icterohaemorrhagiae most likely infecting serogroup $(n=59)$, followed by Autumnalis $(n=8)$. Most uncommon serogroups found were Ballum, Pyrogenes, Canicola, Tarassovi, Grippotyphosa, Celledoni and Australis, with only one reaction each. Co-agglutinations represented $17.7 \%$ of all positive reactions, hampering the identification of the most likely infecting serogroup in 16 samples.

Regarding the sampling sites (Appendix 1), the sample sizes varied from 459 (location 9) to 4 (location 11). Location 9 comprised the garbage dump close to the airport, where 435 egrets were captured. Cats and dogs were captured in all sampling locations. The sampling location 6 (Tres Paus village; $\mathrm{n}=17$ ) was the one with higher percentage of seroreactive animals (35.3\% of all positive samples), and location 11 (DPV village, an irregular settlement; $\mathrm{n}=4$ ) presented no seroreactive animals. The proportion of seroreactive animals according to the sampling locations is presented on Figure 2.

\section{FIGURE 2}

Figure 2: Proportion of seroreactive animals according to the locations that samples were collected.

From the 20 samples destined to culturing leptospires, only one retrieved viable leptospires in selective medium. The strain was named FN115 and further molecular and serological characterization was performed. Serogrouping of the FN115 strain revealed a strong and specific titration against serogroup Pyrogenes $(12,800$ for serogroup Pyrogenes, 1,600 for Icterohaemorrhagiae, and 800 for serogroup Canicola). The MLST analysis revealed that the strain FN115 belongs to sequence type 37 of the MLST scheme, which comprises only $L$. interrogans strains belonging to serogroup Canicola and Pyrogenes, all recovered from dogs and human hosts. All loci presented $100 \%$ identity in the BLAST search except sucA, which presented only one mismatch in a homopolymeric region, which are particularly prone to error in Ion Torrent PGM platform.

\section{Discussion}

This study stands as the most comprehensive investigation ofLeptospira spp. infection in domestic and wild animals from Fernando de Noronha archipelago, also providing the description of the first leptospiral strain ever isolated from an insular setting in Brazil. Overall, most animals reacted against serogroup Icterohaemorrhagiae, corresponding to almost $80 \%$ of all positive samples that the most likely infecting serogroup could 
be determined by MAT. The presence of anti-Leptospira antibodies in animal species from Fernando de Noronha have already been described in 2018 by Moraiset al . (2018), who also found Icterohaemorrhagiae as the main serogroup infecting cattle and rodents in the island. Although prevalence of renal carriage has not been accessed in the present study, the identification of Icterohaemorrhagiae as the most prevalent serogroup in practically all species strongly suggests that rodents play a major role in leptospiral transmission in Fernando de Noronha. Rodents are recognized as the most important reservoir of leptospires worldwide, and renal carriage of different pathogenic serovars causing disease in humans and other animals have been frequently reported (Boey et al., 2019).

Invasive rodents in Fernando de Noronha are subject of major concern, once they can rapidly reproduce and adapt to human activity (Benavidez et al., 2019). Furthermore, invasion of rodents induced devastating effects on local biodiversity, leading to extinction of native wildlife (Russell et al., 2018). These ecosystem disruptions are frequently associated to diminished diversity of species within ecological communities, potentially leading to increased incidence of leptospirosis in insular environments (Derne et al., 2011). Rats, especially black rats, are widely distributed in Fernando de Noronha and density is currently estimated at 3,700 individuals $/ \mathrm{km}^{2}$ in the main island (Russell et al., 2018). In our study, both $R$. rattusand $R$. norvergicus presented agglutinins exclusively against Icterohaemorrhagiae serogroup. Icterohaemorrhagiae have also been identified as the most prevalent serogroup among rodent populations from numerous insular locations (Boey et al., 2019) and strains belonging to this serogroup are considered the main pathogen causing human leptospirosis in the Reunion Islands (Guernier et al., 2016) and French Polynesia (Guernier et al., 2017).

Interestingly, even in face of the high exposure to Icterohaemorrhagiae, the characterization of the leptospiral strain recovered from a black rat revealed infection caused by L. interrogans serogroup Pyrogenes. Pyrogenes strains have been isolated from humans in New Caledonia (Thibeaux et al., 2017), Philippines (Villanueva et al., 2014), Puerto Rico (Valverde et al., 2013) and Mayotte islands (Bourhy et al., 2010). In the Brazilian mainland, two strains belonging to the Pyrogenes serogroup were recovered from a grey opossum (Phylander opossum ) and water rats (Nectomys squamipes) in previous attempts to isolate leptospires from wildlife (Santa Rosa et al., 1975, 1980).

Despite no novel STs was revealed through the MLST analysis, further whole genome sequencing should be performed in future studies for more accurate phylogenetic inference and for a more comprehensive understanding on the pathogenicity of the isolated strain, including key aspects related to host-serovar adaptation. Our results suggest that Fernando de Noronha might present a mixed pattern of leptospiral diversity, where serogroups probably brought along in more recent introduction of rodents coexist with older lineages, as proposed by Guernier et al . (2018) and Dietrich et al. (2018) in Western Indian Ocean islands. Nevertheless, further studies focusing on more in-depth analysis of the leptospiral strains circulating locally should be conducted to fully elucidate the epidemiology of leptospirosis in Fernando de Noronha.

From the 18 seroreactive bovines, 14 had the highest titers against Icterohaemorrhagiae serogroup. These results are markedly different from those found in Brazilian mainland and most parts of the world, where seroreactivity is predominantly associated with serogroup Sejroe, particularly serovar Hardjo (da Silva Pinto et al., 2016). Acute and incidental infection is rare and has been associated with serovars Pomona, Grippotyphosa and Icterohaemorrhagiae (da Silva Pinto et al., 2016). Nine out of the 14 bovines seroreactive for Icterohaemorrhagiae had titers ranging from 400 to 1.600, thus indicating recent exposure to the pathogen. Similarly to bovines, most seroreactive sheep and goats showed the highest titers against Icterohaemorrhagiae, which also diverges from serological data found in continental Brazilian territory, where leptospirosis in small ruminants is also historically associated with serogroup Sejroe, particularly serovar Hardjo (Martins and Lilenbaum, 2014). Horses had the highest seroprevalence found and presented the highest titers mostly against Icterohaemorrhagiae. Although serological surveys in Brazil have confirmed infection caused by serogroup Australis, including horses from Northeast region (Morais et al., 2019), Icterohaemorrhagiae infection has been consistently demonstrated in numerous other studies, currently categorizing this serogroup as the most prevalent among horses in Brazil (Pinto et al., 2017).

Only a small proportion of cats were positive by MAT, and most individuals had titers against serogroup 
Icterohaemorrhagiae. Curiously, none of the 200 cats previously surveyed in Fernando de Noronha by Morais et al. , (2018) presented titers against Leptospira. The epidemiology of feline leptospirosis is yet to be determined, and serovars infecting cats vary greatly across different environmental conditions. Overall, seroreactivity is low, and Pomona has been frequently attributed to leptospiral infection in cats, however infection by serovars from Autumnalis and Ballum serogroups can also occur (Murillo et al., 2020). Under insular conditions, an even wider range of serovars can be found in cats, such as Bataviae in Malaysia (Alashraf et al., 2020), Semaranga in Thailand (Sprissler et al., 2019) and Cynopteri in Saint Kitts (Pratt et al., 2017). Cats have long been believed to control rodent populations, and low proportion of seroreactive cats in Fernando de Noronha requires further investigation, especially considering the high density of rodents found in the island. Still, these findings may indicate naturally acquired immune response to leptospiral infection. Alternatively, most of the cats sampled were found around the inhabited areas and under supervised care by local inhabitants, and although not specifically kept as pets, cats were predominantly subsidized by human feeding, which might attenuate predatory behavior and consequentially lead to less exposure to pathogenic Leptospira .

It is noteworthy that dogs had the most variable serological response in this study. Although Icterohaemorrhagiae was indeed the predominant serogroup found in the canine population, dogs with the highest titers ([?]400) may have possibly presented infection by different serovars such as Whitcombi, Autumnalis and Australis, with the former being the serogroup with the highest titration among all seroreactive animals in the study. These findings are consistent with former studies that also found highly diverse serological response in dogs living on insular settings (Pratt et al., 2017). Such repertoire might be influenced by immunization, which tends to promote paradoxical reactions found in MAT, leading to titration against multiple serovars unrelated to infection. Nevertheless, the dogs included in the study were mostly supervised pets with unrestricted movement and no history of recent immunization, and serovar diversity infecting dogs may reflect intense environmental exposure to leptospires or contact with livestock and peridomestic wildlife reservoirs. Further studies should be addressed to clarify the actual role of dogs in the epidemiology of leptospirosis in Fernando de Noronha, and serological findings may at least indicate dogs as important sentinels for human infection in the island.

Few birds (Gallus domesticus and Bubulcus ibis ) had antibody titers detectable by MAT. The only three seroreactive cattle egrets presented titers against Icterohaemorrhagiae serogroup. Icterohaemorrhagiae could also be detected in one out of the four chickens positive by MAT. Little is known about leptospirosis in birds, but previous reports have also shown low seropositivity in domestic and wildlife birds (Brasil et al., 2013; Acosta et al., 2019). The prevalence found in tegu lizards was relatively high, with four out of the 13 samples reacting against serogroups Icterohaemorrhagiae and Autumnalis, and although the small sample size, similar high prevalence is usually reported in Brazil (Biscola et al., 2011; Paz et al., 2019; Miranda et al., 2020). Still, the role of reptiles as reservoirs of leptospirosis and their risks for public health is debatable (Fornazari, 2017). Few studies have tackled infection and pathogenesis in avian and reptile species, and serological findings in the present study indicate exposure to environmental leptospiral strains circulating locally.

Overall, the serological pattern found in all species highlight the importance of rodents for leptospiral transmission in the island. Rodent control is currently limited to poison bait stations around areas with more infrastructure, which are checked and re-stocked at regular intervals. No rat surveillance in the in the bay area is taken, and invasion from shipped cargo is neglected. Therefore, there is an urgent need for the implementation of a systematic rodent control program. Likewise, the poor sanitary infrastructure conditions found in the island also poses as risk of Leptospira spp. transmission not only to the local human population but also for tourists. The improvement of the sanitary conditions in the archipelago is however a logistical challenge to local managers, since the long distances from the continent and high freight costs make any civil construction intervention very difficult to implement. Although no permanent water stream is found in the archipelago, most of the small farms are located around one large water reservoir, which was used for human consumption in the past. This water reservoir is probably not only associated with the transmission of Leptospira spp. between farm animals, but also wild animals. Cattle egrets, for example, were found at 
the airport strip, which is located between this water reservoir and the archipelago garbage dump.

As the entrance of visitors in Fernando de Noronha is strictly controlled, the adoption of simple educational strategies targeting the awareness of disease transmission or even appropriate testing of symptomatic visitors should be implemented during check-in and check-out procedures as part of a wider surveillance program. Moreover, it is suggested the implementation of an extensive One Health and Health Education Program to control leptospirosis that should involve different health professionals such as physicians, nurses, veterinarians, biologists and health agents.

\section{Acknowledgments}

The authors are grateful to Daniel Ajzenberg, Zenaide M. Morais, Paulo Rogerio Mangini, Tatiane Micheletti, Fernando Ferreira da Silva Filho, Ricardo Araujo, Marcio Andre da Silva, Jose Sergio de Alcantara e Silva, Sandra Cadengue de Santana, Marlos Jose Portela Rego, Carlos Alberto Vieira Batista, Liliane Silvestre Melo, Yeda Maria A. L. V. Araujo, Maria de Fatima Marinho de Souza, Vandilson Rodrigues da Silva, Ricardo Chioratto, Silvio Arruda Vasconcellos, and the Administration of Fernando de Noronha, state district, Pernambuco state, Grupo Boticario, and Instituto Chico Mendes de Conservacao da Biodiversidade ICMBio. This work was supported in part by a scholarship from the Conselho Nacional de Desenvolvimento Cientifico e Tecnologico (CNPq), Brazil (JCRS protocol no 158832/2012-4S). FF, RAD, JSFN, MBH, WL, and OAD are research fellows from CNPq, Brazil.

\section{Conflict of interest}

The authors declare no conflict of interest.

\section{Data availability Statement}

All data are described in the manuscript and raw data can be provided upon request to the corresponding author.

\section{References}

Abrahao, C.R., Russel, J.C., Silva, J.C.R., Ferreira, F., Dias, R.A. (2019). Population assessment of a novel island invasive: tegu (Salvator merianae) of Fernando de Noronha. Isl. Invasives Scaling up to Meet Chall. 313-321. doi : 10.2305/IUCN.CH.2019.SSC-OP.62.en.

Acosta, I.C.L., Souza-Filho, A.F., Munoz-Leal, S., Soares, H.S., Heinemann, M.B., Moreno, L., GonzalezAcuna, D. and Gennari, S.M. (2019). Evaluation of antibodies against Toxoplasma gondii andLeptospira spp. in Magellanic penguins (Spheniscus magellanicus ) on Magdalena Island, Chile. Vet. Parasitol. Reg. Stud. Reports, 16. doi : 10.1016/j.vprsr.2019.100282.

Alashraf, A.R., Lau, S.F., Khairani-Bejo, S., Khor, K.H., Ajat, M., Radzi , R., Roslan, M.A. and Abdul Rahman, M.S. (2020). First report of pathogenic Leptospira spp. isolated from urine and kidneys of naturally infected cats. PLoS One 15, 1-13. doi : 10.1371/journal.pone.0230048.

Bandara, M., Ananda, M., Wickramage, K., Berger E., and Agampodi, S. (2014). Globalization of leptospirosis through travel and migration. Global. Health, 10, 1-9. doi : 10.1186/s12992-014-0061-0.

Barragan, V., Chiriboga, J., Miller, E., Olivas, S., Birdsell, D., Hepp, C., Hornstra, H., Schupp, J.M., Morales, M., Gonzalez, M., Reyes, S., de la Cruz, C., Keim, P., Hartskeerl, R., Trueba G., and Pearson, T. (2016). High Leptospira Diversity in Animals and Humans Complicates the Search for Common Reservoirs of Human Disease in Rural Ecuador. PLoS Negl. Trop. Dis. 10, 1-14. doi : 10.1371/journal.pntd.0004990.

Benavidez, K.M., Guerra, T., Torres, M., Rodriguez, D., Veech, J.A., Hahn, D., Miller, R.J., Soltero, F. V., Ramirez, A.E.P., Perez de Leon, A., and Castro-Arellano, I. (2019). The prevalence of Leptospiraamong invasive small mammals on Puerto Rican cattle farms. PLoS Negl. Trop. Dis. 13, 1-16. doi : 10.1371/journal.pntd.0007236. 
Biscola, N.P., Fornazari, F., Saad, E., Richini-Pereira, V.B., Campagner, M. V., Langoni , H., Barraviera, B., and Ferreira, R.S. (2011). Serological investigation and PCR in detection of pathogenic leptospires in snakes. Pesqui. Vet. Bras. 31, 806-811.doi : 10.1590/S0100-736X2011000900013.

Biscornet, L., Dellagi, K., Pages, F., Bibi, J., de Comarmond, J., Melade, J., Govinden, G., Tirant, M., Gomard, Y., Guernier, V., Lagadec, E., Melanie, J., Rocamora, G., Le Minter, G., Jaubert, J., Mavingui, P., and Tortosa, P. (2017). Human leptospirosis in Seychelles: A prospective study confirms the heavy burden of the disease but suggests that rats are not the main reservoir. PLoS Negl. Trop. Dis. 11, 1-22.doi : 10.1371/journal.pntd.0005831.

Boey, K., Shiokawa, K., and Rajeev, S. (2019). Leptospirainfection in rats: A literature review of global prevalence and distribution. PLoS Negl. Trop. Dis. 13, 1-24. doi : 10.1371/journal.pntd.0007499.

Boonsilp, S., Thaipadungpanit, J., Amornchai, P., Wuthiekanun, V., Bailey, M.S., Holden, M.T.G., Zhang, C., Jiang, X., Koizumi, N., Taylor, K., Galloway, R., Hoffmaster, A.R., Craig S., Smythe, L.D., Hartskeerl, R.A., Day, N.P., Chantratita, N., Feil, E.J., Aanensen, D.M., Spratt, B.G., and Peacock, S.J. (2013). A Single Multilocus Sequence Typing (MLST) Scheme for Seven Pathogenic Leptospira Species. PLoS Negl. Trop. Dis. 7, e1954. doi : 10.1371/journal.pntd.0001954.

Bourhy, P., Collet, L., Clement, S., Huerre, M., Ave, P., Giry, C., Pettinelli, F., and Picardeau, M. (2010). Isolation and Characterization of New Leptospira Genotypes from Patients in Mayotte (Indian Ocean). PLoS Negl. Trop. Dis. 4, 1-10. doi : 10.1371/journal.pntd.0000724.

Brasil, A., Parentoni, R., Farias, R., Nery, T., Vasconcellos, S., and de Azevedo, S.S. (2013) Anticorpos anti-Leptospira spp. em animais mantidos em cativeiro na Paraiba. Semin. Ciencias Agrarias, 34, 2945. doi : 10.5433/1679-0359.2013v34n6p2945.

Cassadou, S., Rosine, J., Flamand, C., Escher, M., Ledrans, M., Bourhy, P., Picardeau, M., and Quenel, P. (2016). Underestimation of Leptospirosis Incidence in the French West Indies. PLoS Negl. Trop. Dis. 10, 1-10. doi : 10.1371/journal.pntd.0004668.

Cerqueira, G.M., and Picardeau, M. (2009). A century ofLeptospira strain typing. Infect. Genet. Evol. 9, 760-768. doi : 10.1016/j.meegid.2009.06.009.

Costa, F., Hagan, J.E., Calcagno, J., Kane, M., Torgerson, P., Martinez-Silveira, M.S., Stein, C., AbelaRidder, B., and Ko, A.I. (2015). Global Morbidity and Mortality of Leptospirosis: A Systematic Review. PLoS Negl. Trop. Dis. 9, 1-19. doi : 10.1371/journal.pntd.0003898.

da Silva Pinto, P., Libonati, H., Penna, B., and Lilenbaum, W. (2016). A systematic review on the microscopic agglutination test seroepidemiology of bovine leptospirosis in Latin America. Trop. Anim. Health Prod. 48, 239-248. doi : 10.1007/s11250-015-0954-9.

De Morais, E.G.F., Rodrigues Magalhaes, F.J., De Lima Filho, C.D.F., Brandespim, D.F., De Oliveira, P.R.F., Da Costa, D.F., De Azevedo, S.S., and Mota, R.A. (2018). Geo-epidemiological study of Leptospira spp. Infection in cattle, feral cats and rodents of the Fernando de Noronha Island, Brazil. Acta Sci. Vet. 46, 1-9.doi :10.22456/1679-9216.79176.88400.

De Vries, S.G., Visser, B.J., Stoney, R.J., Wagenaar, J.F.P., Bottieau, E., Chen, L.H., Wilder-Smith, A., Wilson, M., Rapp, C., Leder, K., Caumes, E., Schwartz, E., Hynes, N.A., Goorhuis, A., Esposito, D.H., Hamer, D.H., and Grobusch, M.P. (2018). Leptospirosis among returned travelers: A geosentinel site survey and multicenter analysis-1997-2016. Am. J. Trop. Med. Hyg. 99, 127-135. doi : 10.4269/ajtmh.18-0020.

Derne, B.T., Fearnley, E.J., Lau, C.L., Paynter, S., and Weinstein, P. (2011). Biodiversity and leptospirosis risk: A case of pathogen regulation? Med. Hypotheses, 77, 339-344. doi : 10.1016/j.mehy.2011.05.009.

Desvars, A., Michault, A., and Bourhy, P. (2013). Leptospirosis in the western Indian Ocean islands: what is known so far?. Vet. Res. 44, 1-11. doi : 10.1186/1297-9716-44-80. 
Dias, R., Chaves, R., De Souza, G., Goncales, A., Ikuta, C., Morais, Z., Marcili, A., Ferreira, F., Amaku, M., Ferreira Neto, J., and Vasconcellos, S. (2011). Exotic rodent species in one South Atlantic Ocean island : House mouse (Mus musculus ) infestation in Trindade Island, Brazil. Pest Manag. e Salut. pubblica. 23, 81-92.

Dias, R.A., Abrahao, C.R., Micheletti, T., Mangini, P.R., de Oliveira Gasparotto, V.P., de Jesus Pena, H.F., Ferreira, F., Russell, J.C. and Silva, J.C.R. (2017). Prospects for domestic and feral cat management on an inhabited tropical island. Biol. Invasions. 19, 2339-2353,doi : 10.1007/s10530-017-1446-9.

Dietrich, M., Gomard, Y., Lagadec, E., Ramasindrazana, B., Le Minter, G., Guernier, V., Benlali, A., Rocamora, G., Markotter, W., Goodman, S.M., Dellagi, K. and Tortosa, P. (2018). Biogeography ofLeptospira in wild animal communities inhabiting the insular ecosystem of the western Indian Ocean islands and neighboring Africa article. Emerg. Microbes Infect. 7. doi : 10.1038/s41426-018-0059-4.

Dikken, H., and Kmety, E. (1978). Chapter VIII: Serological Typing Methods of Leptospires. Methods Microbiol. doi : 10.1016/S0580-9517(08)70493-8.

Faine, S., Adler, B., Bolin, C., and Perolat, P. (1999).Leptospira and Leptospirosis (2nd Edition). Book, MedSci, Armadale, Australia.

Felzemburgh, R.D.M., Ribeiro, G.S., Costa, F., Reis, R.B., Hagan, J.E., Melendez, A.X.T.O., Fraga, D., Santana, F.S., Mohr, S., dos Santos, B.L., Silva, A.Q., Santos, A.C., Ravines, R.R., Tassinari, W.S., Carvalho, M.S., Reis, M.G., and Ko, A.I. (2014). Prospective Study of Leptospirosis Transmission in an Urban Slum Community: Role of Poor Environment in Repeated Exposures to the Leptospira Agent. PLoS Negl. Trop. Dis. 8. doi : 10.1371/journal.pntd.0002927.

Fornazari, F. (2017). Are Reptiles Reservoirs of Leptospirosis? A Brief Discussion Based on Serological Studies. Ecohealth. 14, 203-204.doi : 10.1007/s10393-017-1243-z.

Gasparini, J.L., Peloso, P.L., and Sazima, I. (2007). New opportunities and hazards brought by humans to the island habitat of the skink Euprepis atlanticus. Herpetol. Bull. 100. 30-33.

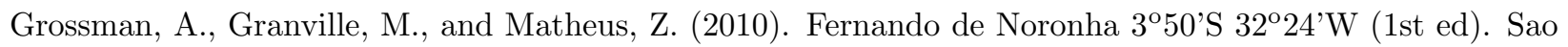
Paulo:Bei.

Guernier, V., Goarant, C., Benschop, J., and Lau, C.L. (2018). A systematic review of human and animal leptospirosis in the Pacific Islands reveals pathogen and reservoir diversity. PLoS Negl. Trop. Dis. 12, 1-32. doi : 10.1371/journal.pntd.0006503.

Guernier, V., Lagadec, E., Cordonin, C., Le Minter, G., Gomard, Y., Pages, F., Jaffar-Bandjee, M.C., Michault, A., Tortosa, P., and Dellagi, K., (2016). Human Leptospirosis on Reunion Island, Indian Ocean: Are Rodents the (Only) Ones to Blame?. PLoS Negl. Trop. Dis. 10, 1-19.doi : 10.1371/journal.pntd.0004733.

Guernier, V., Richard, V., Nhan, T., Rouault, E., Tessier, A., and Musso, D. (2017). Leptospira diversity in animals and humans in Tahiti, French Polynesia. PLoS Negl. Trop. Dis. 11, 1-16.doi : 10.1371/journal.pntd.0005676.

IBGE - Instituto Brasileiro de Geografia e Estatistica (2019). Cidades e Estados: Fernando de Noronha - PE, Brasil [Online]. Retrieved from: https://www.ibge.gov.br/cidades-e-estados/pe/fernando-de-noronha.html.

Martins, G., and Lilenbaum, W. (2014). Leptospirosis in sheep and goats under tropical conditions. T rop. Anim. Health Prod. 46, 11-17.doi : 10.1007/s11250-013-0480-6.

Miranda, J.M.S., de S. Rocha, K., Monteiro, L.H., Baia, I.W.M., Monteiro, T.R.M., Brito, J. da S., Mesquita, E.Y.E., and de Moraes, C.C.G. (2020). Presence of anti-Leptospira spp. Antibodies in captive yellow-spotted river turtles (Podocnemis unifilis ) in the eastern amazon. Cienc. Rural. 50, 12-15. doi : 10.1590/0103$8478 \mathrm{cr} 20190088$. 
Morais, D. de A., Bezerra, C. de S., dos Anjos, D.M., Nunes, B.C., Nogueira, D.B., Pequeno, N.F., da Costa, D.F., Higino, S.S.D.S., Azevedo, S.S., and Alves, C.J. (2019). Spatial distribution of equine seroreagent to Leptospira spp. in Northeastern Brazil. Brazilian J. Vet. Res. Anim. Sci. 56, 1-8. doi : 10.11606/issn.16784456.bjvras.2019.162784.

Murillo, A., Goris, M., Ahmed, A., Cuenca, R., and Pastor, J. (2020). Leptospirosis in cats: Current literature review to guide diagnosis and management. J. Feline Med. Surg. 22, 216-228. doi : 10.1177/1098612X20903601.

Paz, L.N., Hamond, C., Dias, C.S., Curvelo, V.P., Medeiros, M.A., Oria, A.P., and Pinna, M.H. (2019). Detection of Leptospira spp. in Captive Broad-Snouted Caiman (Caiman latirostris ). Ecohealth 16, 694700. doi : 10.1007/s10393-019-01452-0.

Petrakovsky, J., Bianchi, A., Fisun, H., Najera-Aguilar, P., and Pereira, M.M. (2014). Animal leptospirosis in Latin America and the caribbean countries: Reported outbreaks and literature review (2002-2014). I nt. J. Environ. Res. Public Health. doi : 10.3390/ijerph111010770.

Pinto, P.S., Libonati, H., and Lilenbaum, W. (2017). A systematic review of leptospirosis on dogs, pigs, and horses in Latin America. Trop. Anim. Health Prod. 49, 231-238. doi : 10.1007/s11250-016-1201-8.

Pratt, N., Conan, A., and Rajeev, S. (2017). LeptospiraSeroprevalence in Domestic Dogs and Cats on the Caribbean Island of Saint Kitts. Vet. Med. Int. 1-6. doi : 10.1155/2017/5904757.

Pratt, N., and Rajeev, S. (2018). Leptospira seroprevalence in animals in the Caribbean region: A systematic review. Acta Trop. 182, 34-42. doi : 10.1016/j.actatropica.2018.02.011.

Russell, J.C., Abrahao, C.R., Silva, J.C.R., and Dias, R.A. (2018). Management of cats and rodents on inhabited islands: An overview and case study of Fernando de Noronha, Brazil. Perspect. Ecol. Conserv. 16, 193-200. doi : 10.1016/j.pecon.2018.10.005.

Santa Rosa, C.A., Sulzer, C.R., Giorgi, W., da Silva, A.S., Yanaguita, R.M., and Lobao, A.O. (1975). Leptospirosis in wildlife in Brazil: isolation of a new serotype in the pyrogenes group. Am. J. Vet. Res. 36, 1363-1365.

Santa Rosa, C.A., Sulzer, C.R., Yanaguita, R.M., and Da Silva, A.S. (1980). Leptospirosis in wildlife in Brazil: isolation of serovars canicola, pyrogenes and grippotyphosa. Int. J. Zoonoses. 7, 40-43.

Schneider, M.C., Leonel, D.G., Hamrick, P.N., de Caldas, E.P., Velasquez, R.T., Mendigana Paez, F.A., Gonzalez Arrebato, J.C., Gerger, A., Maria Pereira, M., and Aldighieri, S. (2017). Leptospirosis in Latin America: exploring the first set of regional data. Rev. Panam. Salud Publica 41, 1-9. doi : 10.26633/rpsp.2017.81.

Sprissler, F., Jongwattanapisan, P., Luengyosluechakul, S., Pusoonthornthum, R., Prapasarakul, N., Kurilung, A., Goris, M., Ahmed, A., Reese, S., Bergmann, M., Dorsch, R., Klaasen, H.L.B.M., and Hartmann, K. (2019). Leptospira infection and shedding in cats in Thailand. Transbound. Emerg. Dis. 66, 948-956. doi : 10.1111/tbed.13110.

Thibeaux, R., Geroult, S., Benezech, C., Chabaud, S., Soupe-Gilbert, M.E., Girault, D., Bierque, E., and Goarant, C. (2017). Seeking the environmental source of Leptospirosis reveals durable bacterial viability in river soils. PLoS Negl. Trop. Dis. 11, 1-14. doi : 10.1371/journal.pntd.0005414.

Valverde, M. de los A., Goris, M.G.A., Gonzalez, V., Anchia, M.E., Diaz, P., Ahmed, A., and Hartskeerl, R.A. (2013). New serovars ofLeptospira isolated from patients in Costa Rica: implications for public health. J. Med. Microbiol. 62, 1263-1271. doi : 10.1099/jmm.0.058545-0.

Victoriano, A.F.B., Smythe, L.D., Gloriani-Barzaga, N., Cavinta, L.L., Kasai, T., Limpakarnjanarat, K., Ong, B.L., Gongal, G., Hall, J., Coulombe, C.A., Yanagihara, Y., Yoshida, S., and Adler, B. (2009). Leptospirosis in the Asia Pacific region. BMC Infect. Dis. 9, 1-9.doi : 10.1186/1471-2334-9-147. 
Villanueva, S.Y.A.M., Saito, M., Baterna, R.A., Estrada, C.A.M., Rivera, A.K.B., Dato, M.C., Zamora, P.R.F.C., Segawa, T., Cavinta, L.L., Fukui, T., Masuzawa, T., Yanagihara, Y., Gloriani, N.G., and Ichi Yoshida, S. (2014). Leptospira -rat-human relationship in Luzon, Philippines. Microbes Infect. 16, 902-910. doi : 10.1016/j.micinf.2014.07.001.

Warnasekara, J., Koralegedara, I., and Agampodi, S. (2019). Estimating the burden of leptospirosis in Sri Lanka; A systematic review. BMC Infect. Dis. 19, 119. doi : 10.1186/s12879-018-3655-y.

Zarantonelli, L., Suanes, A., Meny, P., Buroni, F., Nieves, C., Salaberry, X., Briano, C., Ashfield, N., Da Silva Silveira, C., Dutra, F., Easton, C., Fraga, M., Giannitti, F., Hamond, C., Macias-Rioseco, M., Menendez, C., Mortola, A., Picardeau, M., Quintero, J., Rios, C., Rodriguez, V., Romero, A., Varela, G., Rivero, R., Schelotto, F., Riet-Correa, F., and Buschiazzo, A. (2018). Isolation of pathogenicLeptospira strains from naturally infected cattle in Uruguay reveals high serovar diversity, and uncovers a relevant risk for human leptospirosis. PLoS Negl. Trop. Dis. 12, 1-22. doi : 10.1371/journal.pntd.0006694.

\section{Hosted file}

Table_1.docx available at https://authorea.com/users/344422/articles/470962-seroepidemiologyof-leptospirosis-and-molecular-characterization-of-the-first-leptospira-strain-isolatedfrom-fernando-de-noronha-archipelago-brazil

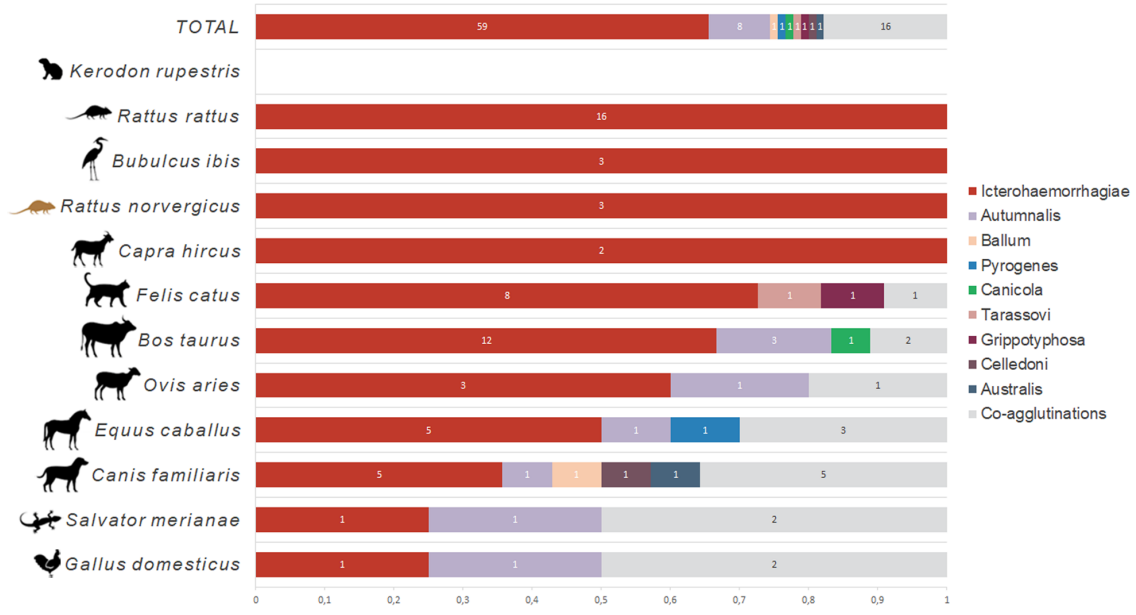



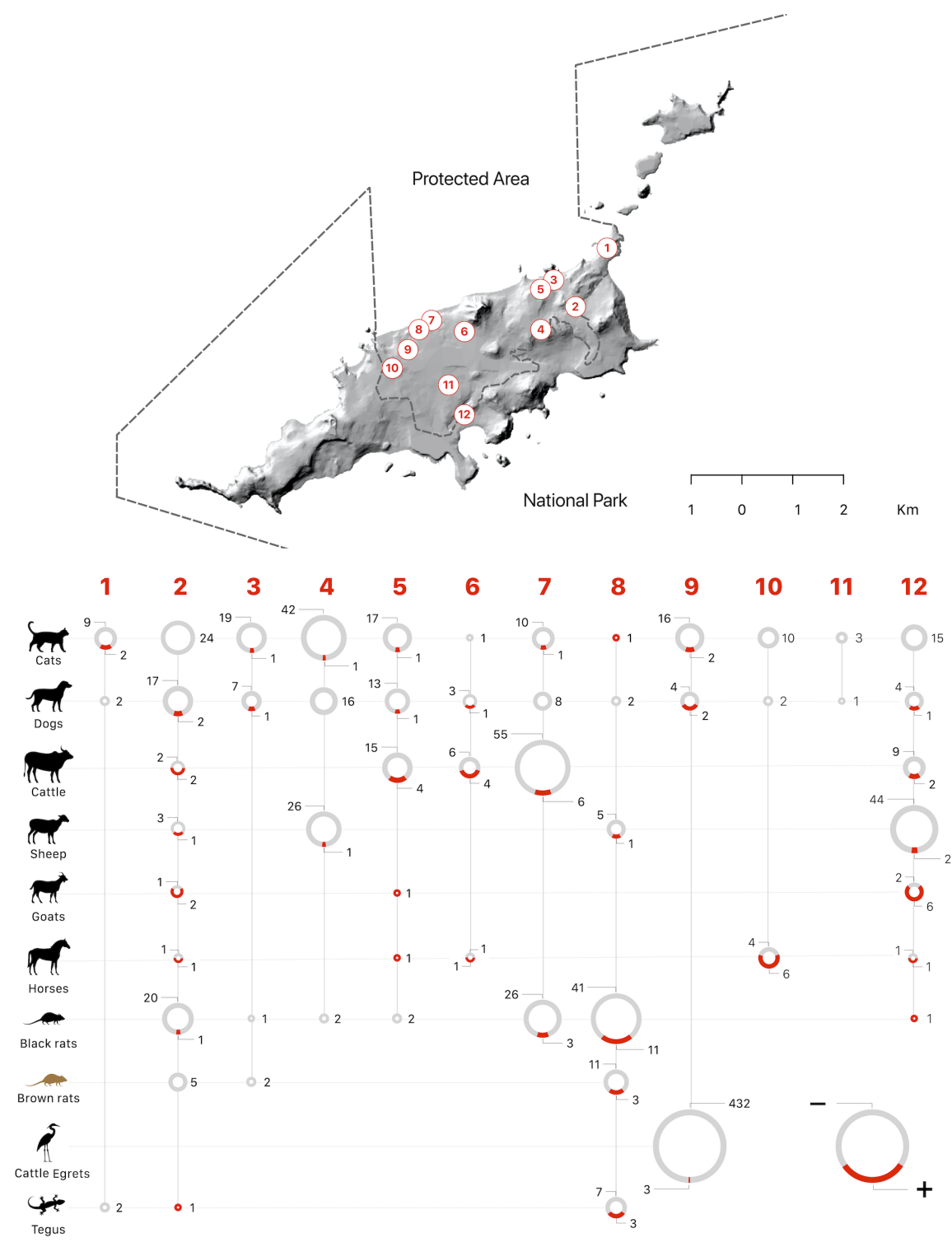